\title{
LAS FUERZAS ARMADAS EN ESPAÑA: ¿último bastión del franquismo?
}

Rafael C. Martínez Martínez*

Fecha de Recepción: 31 de octubre de 2011

Fecha de Aprobación: 21 de Noviembre de 2011

Artículo de Reflexión

\begin{abstract}
Resumen
Las complicadas relaciones civiles-militares en España tienen como elemento subyacente los duros años de dictadura franquista. En esa tesitura, preguntarse si las fuerzas armadas españolas han culminado su consolidación democrática y han dejado de ser poder político, para convertirse en administración militar resulta pertinente. El presente trabajo sustentado mediante datos de opinión pública y datos extraídos de diversos entrevistas y cuestionarios realizados a los futuros mandos de las fuerzas armadas españolas, devela qué progresos, intensos, se han realizado en ese sentido y qué déficits quedan todavía por solventar; concluyendo en el innegable talante democrático y asunción de la supremacía civil por parte de la oficialidad y suboficialidad más joven del ejército (Tierra, Armada y Aire) Español.
\end{abstract}

\section{Palabras clave}

Relaciones civiles-militares, consolidación democrática, fuerzas armadas

\section{THE ARMED FORCES IN SPAIN: last bastion of Franco?}

\begin{abstract}
The complicated relations civilians - militaries, in Spain have as underlying element the hard years of pro-Franco dictatorship. In this attitude, to the wonder if the Spanish armed forces have reached his democratic consolidation and have stopped being a political power, to turn into military administration turns out to be pertinent. The present
\end{abstract}

\footnotetext{
[Melilla (España), 1965] es profesor de Ciencias Políticas y Administración de la Universidad de Barcelona. Él tiene una licenciatura en Derecho en la Universidad de Zaragoza (España) y Pau (Francia) y un DEA en Derecho Público por este último y el doctorado en Derecho con una tesis sobre el Partido Socialista francés en la Universidad de Zaragoza. Ganó el premio extraordinario de doctorado en el área de humanidades y ciencias sociales en la Universidad de Zaragoza y el Premio Nacional de Investigación de la Paz, Seguridad y Defensa del Ministerio de Defensa de 2003.

Ha sido asistente de investigación en las Universidades de Pau y Zaragoza; Profesor de la Universidad de Educación a Distancia y la Universidad Abierta de Cataluña. Ha sido profesor visitante en la Universidad de Lyon II, Universidad Montpellier I, Universidad Católica del Uruguay y Universidad Católica Central en El Salvador. Ha sido investigador visitante en Fondation Nationale des Sciences Politiques in Paris (Francia).

Sus publicaciones más importantes son: Sistemas de gobierno, partidos y territorio (2000) con Cesareo R. Aguilera de Prat (Ed. Tecnos), La elección presidencial mediante Doble Vuelta en América Latina (2004) (Ed. ICPS), La seguridad desde las dos orillas (2006) con Joseph S. Tulchin (Ed. CIDOB) y Los mandos de las Fuerzas armadas españolas del siglo XXI (2007), (Ed CIS), una obra que ha ganado el premio al mejor libro del año por la Ciencia Política y Asociación Española de Administración (AECPA) en 2007. E-mail: rafa.martinez@ub.edu
} 
work was made, by means of data of the public opinion and information extracted of interviews and questionnaires realized to the futures leaderships of the Spanish armed forces, reveal a progresses, intense, will have been realized in this sense and what deficits is still to settle; concluding in the undeniable democratic mien and assumption of the civil supremacy for the part of the official and subofficial more young of the Spanish army (Land, Navy and Air).

\title{
Keywords
}

Civil-military relations, democratic consolidation, armed forces

\section{AS FORÇAS ARMADAS NA ESPANHA: o último bastião de Franco?}

\begin{abstract}
Resumo
As complicadas relações civis-militares em Espanha têm como elemento subyacente nos duros anos de ditadura franquista. Nessa tesitura, perguntar-se se as forças armadas espanholas culminaram sua consolidación democrática e deixaram de ser poder político, para converter-se em administração militar resulta pertinente. $\mathrm{O}$ presente trabalho sustentado mediante dados de opinião pública e dados extraídos de diversos entrevistas e cuestionarios realizados aos futuros comandos das forças armadas espanholas, devela que progressos, intensos, se realizaram nesse sentido e daí déficits ficam ainda por solventar, concluindo no innegable talante democrático e assunção da supremacía civil por parte da oficialidad e suboficialidad mais jovem do exército (Terra, Armada e Ar) Espanhol.
\end{abstract}

\section{Palavras-chave}

Relações civis-militares, consolidación democrática, forças armadas.

\section{INTRODUCCIÓN}

La historia de las fuerzas armadas (en adelante FAS) y de las instituciones españolas ha sido larga y compleja (Payne, 1968, 1977; Serrano, 1976, 1984; Ballbé, 1983). Ya en el siglo XIX los "ayacuchos" impulsan la revolución liberal y democratizadora y en las guerras carlistas apoyan a la regente Cristina y a la reina Isabel II. Desde entonces su papel ha sido importante; no en vano, se puede afirmar que a falta de una burguesía que encabezase la revolución liberal fueron las FAS las que la pilotaron. Sin embargo, tras el asesinato del General liberal Prim, los avatares de la Restauración - General Martínez Campos-... las FAS entran en el siglo XX con el legado de la crisis de 1898 y las guerras

1 Llamados así por volver de la batalla de Ayacucho coloniales; abandonan su posición liberal y se hacen más conservadores. Esta deriva, como lamentablemente todos sabemos, culminará es una fraticida guerra civil2. Todo ese contradictorio legado histórico sin embargo queda diluido por el impacto social que alcanza la guerra civil, hasta el punto de poder afirmar que las relaciones civilesmilitares contemporáneas en España comienzan en la guerra civil, habiendo casi desaparecido del imaginario colectivo el pasado progresista o conservador de las mismas y arrancando desde

2 "Los siglos XIX y XX, doscientos años en los que la presidencia del Consejo de Ministros ha sido ocupada por militares mucho más de lo habitual en cualquier otro país de nuestro entorno. Los militares en política; los políticos de procedencia militar; los políticos con mentalidad militar; lo militar en la política, el pan nuestro de cada día. El militarismo en suma." (Fernández, 2004, p. 2) 
su posición de tropas combatientes contra el gobierno democráticamente elegido de la II República.

Tras tres años de enfrentamiento, la victoria de las tropas insurgentes implicó la conversión de la entonces República española en un sistema totalitario con Franco a la cabeza. La dictadura franquista no fue una dictadura militar, sino la dictadura de un militar que artículo un triángulo de poder sobre el que se sentía protegido y con el que controlaba a la sociedad desde todos los ángulos: el ejército, la iglesia y el partido fascista único FET-JONS.

Durante los casi cuarenta años de régimen totalitario-autoritario son millones los españoles varones que como conscriptos han pasado un periodo de sus vidas -servicio militar- como soldados sometidos a las órdenes de militares fascistas y bajo el dominio de un poder político opresor. El dictador murió en una cama de hospital en noviembre de 1975 y hubo que esperar hasta verano de 1976 para que el Rey Juan Carlos I aceptase la dimisión de Arias Navarro-último jefe de gobierno franquista y primer jefe de gobierno tras la muerte del General Franco- y nombrase a Adolfo Suárez. Sólo entonces pudo iniciarse, no sin enormes dificultades, un proceso de transición a la democracia. La paulatina apertura democrática que las reformas del gobierno Suárez implicaban provocó, en más de una ocasión, airadas contestaciones de la cúpula militar. Tres esencias eran intocables según el criterio de ésta: la unidad de la patria, el catolicismo y la monarquía. Así las cosas, la legalización del partido comunista, la articulación territorial en comunidades autónomas, la discusión sobre si la forma de Estado debería ser una Monarquía o una República, la aconfesionalidad del Estado y el permanente y duro azote de la banda terrorista ETA en aquellos años, dio alas a un grupo de militares -pequeño, aunque con mucho poder todavía- nostálgicos del franquismo y refractarios con la democracia, hasta el extremo de intentar un golpe de Estado en 1981.

El triunfo del proceso democrático rompió con todos los estigmas del pasado y permitió, por primera vez en la historia española, la convivencia pacífica de todos. En el estricto ámbito militar hay que destacar las reformas emprendidas por el vicepresidente primero del gobierno de Adolfo Suárez, General Gutiérrez Mellado, culminadas y reforzadas por el ministro de defensa del primer gobierno socialista, Narcís Serra. A través de ellas se pretendió (i) modernizar las fuerzas armadas, (ii) apartarlas de poder político transformándolas en administración militar al servicio del gobierno $y$ (iii) reducir su volumen hasta cifras coherentes con las necesidades y amenazas de un Estado democrático rodeado de socios comunitarios. El propio Serra (2002) nos ha marcado de un modo más extenso cuáles son los retos y cambios que han de producirse en la instancia militar para convertirla, en el marco de un proceso de transición democrática, en una administración militar democrática capaz de articular unas relaciones civiles-militares asentadas en la irrenunciable premisa de la supremacía civil ${ }^{3}$. Así durante el periodo inicial del proceso democratizador se debe retirar la presencia militar del poder político y aprobar una ley que establezca claramente su marco orgánico y funciones. La consolidación democrática requiere profundos cambios en las dinámicas del proceso político y en los actores políticos insertos en él. De hecho, en la administración

3 Narcis Serra (2002), exministro de Defensa y exvicepresidente del gobierno de España, desde el ejemplo que representa para él la modernización y reforma de las fuerzas armadas españolas ha fijado, conceptualmente, las reformas que estima imprescindibles en cualquier sistema político para superar con éxito las fases de transición y consolidación. Así, durante la transición cree necesario: (i) modificar la legislación sobre Defensa Nacional y (ii) reducir la presencia militar en otros campos de la administración. Para llegar a la anhelada consolidación democrática cree imprescindible: (i) la elaboración gubernamental de la política militar, (ii) la eliminación de los privilegios militares, (iii) la evolución del concepto de profesión militar desde el institucionalismo hacia el ocupacionalismo y (iv) la definición de nuevas misiones que las aleje del control interior. Alcanzado este nuevo escenario y con el fin de mantener y reforzar el carácter democrático de las FAS cree oportuno: (i) determinar gubernamental o parlamentariamente, con nitidez, el grado de autonomía de la institución, (ii) integrar a la sociedad en la definición de la política de defensa y (iii) definición de nuevas misiones, normalmente operativos internacionales 
militar será imprescindible la desaparición de sus privilegios, la modernización de sus capacidades y estructuras, así como la fijación gubernamental de sus objetivos y misiones. Una vez asentada la democracia es el momento de apuntalar la cultura ciudadana en seguridad y defensa, de asumir retos internacionales; así como de determinar el nivel de autonomía que se les otorga para el cumplimiento de sus tareas.

En 1986, consolidada la democracia española y tras ser aceptados como socios de pleno derecho en la Unión Europea, España tenía ante sí todavía múltiples retos importantes. Uno de ellos, a tenor de los nefastos precedentes de relaciones entre FAS y sociedad, era construir unas fructíferas y fluidas relaciones civiles-militares. El militar español no estaba socialmente bien considerado, era una profesión fuertemente desprestigiada y con una negativa carga política. La sociedad española no era pacifista, sino antimilitarista. Por otro lado, la importantísima presencia de bases y tropas norteamericanas en suelo español, y la sensación de violación de la soberanía que ello comportaba, no ayudaban a limar esa tendencia. La sociedad identificaba ejército con franquismo, con ocupación, y eliminar esa percepción requería mucha, y muy paciente, actividad.

A mayor abundamiento, a finales de los ochenta, tiene mucho que ver con lo dicho, la extraordinaria dimensión que cobró la objeción de conciencia al servicio militar. Lo que estaba en cuestión no era si el servicio militar obligatorio era o no parte de la revolucionaria idea de "nación en armas". Lo cuestionado era la inutilidad de una obligación mal concebida, en unas FAS arcaicas y socialmente consideradas último bastión de un ya erradicado franquismo. Ante el crecimiento exponencial de los objetores, la clase política fue incapaz de articular una solución satisfactoria y consensuada e inició una vertiginosa carrera electoralista de reducción de la duración del servicio militar hasta su erradicación a finales de siglo. Sin embargo, esa medida, lejos de engrasar las relaciones civiles militares, supuso un enfriamiento bárbaro y un nuevo problema para los gobiernos: La extrema dificultad para reclutar soldados voluntarios profesionales. Ante el creciente alejamiento social para con las FAS españolas, los sucesivos gobiernos han postulado la necesidad de crear una conciencia ciudadana de la necesidad de la defensa ${ }^{4}$ una cultura política de defensa (Martínez, 2007a).

Sin embargo, desde mediados de los noventa la tendencia está cambiando. Dos eventos van a ser cruciales en la normalización cívica para con las políticas de seguridad y defensa. Por un lado, las victorias electorales socialistas durante los ochenta tuvieron, como uno de sus principales temas de campaña, la pretensión de salir de la OTAN. Sin embargo, el gobierno socialista en 1986, tras el ingreso en la CEE, convocó un referéndum en el que la postura gubernamental, sorpresivamente para sus votantes, fue la defensa del "Sí a la permanencia". El que fuera entonces ministro portavoz, Javier Solana Madariaga, años después -1995-, siendo ministro de asuntos exteriores, fue nombrado secretario general de la OTAN. Una vez concluido su mandato, la UE quiso aprovechar su experiencia y el consenso que su figura causaba entre los socios europeos y lo nombró máximo representante de la PESC. Por otro lado, en este periodo, las fuerzas armadas españolas comenzaron un creciente despliegue en operaciones de paz en Centroamérica, África, los Balcanes, Afganistán, etc. Igualmente colaboraron en catástrofes y calamidades en ámbito nacional e internacional. La presencia de un político español en un puesto clave para la seguridad mundial y europea ha acercado a los españoles a la política de Defensa como una realidad democrática, necesaria y alejada de los tópicos fascistas. Y por su parte, las nuevas misiones que el ejército ha ido emprendiendo les han prestigiado mucho socialmente (tabla 1). Sin embargo, esa mejora

4 Sirva como dato que, todavía hoy, ante la pregunta ¿en qué circunstancias considera usted legitimada la actuación de las FAS españolas? Sólo un $65 \%$ cree legítima la intervención tras el ataque de tropas de otro país en suelo patrio. Es decir, un $35 \%$ de los españoles no considera legítima la intervención de su propio ejército ni en el caso de la tarea para la que fueron concebidos: la defensa territorial. 
sustancial en la valoración que la opinión pública tiene de los militares se ve contrastada con la opinión peyorativa que los militares creen que la sociedad tiene de ellos (tabla 2).

Tabla 1. Valoración de la capacitación profesional de los militares según la opinión pública

\begin{tabular}{|l|c|c|c|c|c|c|c|c|c|}
\hline & 1986 & $1987^{*}$ & 1989 & 1997 & 1998 & 1999 & 2000 & 2002 & 2005 \\
\hline Muy capacitados & 4 & & 6.2 & 4.1 & 5.6 & 5.3 & 8.6 & 6.3 & 8.6 \\
\hline Bastante capacitados & 33 & $37^{(1)}$ & 45.3 & 40.4 & 41.3 & 45.1 & 48.1 & 48.0 & 51.0 \\
\hline Poco capacitados & 38 & $47^{(2)}$ & 25.5 & 32.0 & 28.0 & 25.0 & 19.6 & 22.8 & 20.6 \\
\hline Nada capacitados & 9 & & 3.3 & 5.0 & 3.9 & 3.3 & 2.9 & 2.6 & 2.2 \\
\hline Ns/Nc & 16 & 16 & 19.7 & 18.5 & 21.2 & 21.3 & 20.9 & 20.5 & 17.5 \\
\hline
\end{tabular}

* unidad de estudios de la SEGENTE (Secretaría General Técnica del Ministerio de Defensa) de 1987 "la imagen social de la defensa en la juventud"

(1) porcentaje correspondiente a "muy y bastante capacitadas"

(2) porcentaje correspondiente a "poco y nada capacitadas"

Fuente: Estudios 1518, 1784, 2234, 2277, 2317, 2379, 2447 y 2592 del Centro de Investigaciones Sociológicas.

Elaboración propia

Tabla 2. Pensando en el futuro de los ejércitos ¿̇cuál de las siguientes opiniones le parece mayoritaria en la sociedad?

\begin{tabular}{|l|c|c|c|c|c|}
\hline \multicolumn{1}{|c|}{ Posibilidades futuras } & $\begin{array}{c}\text { Opinión } \\
\text { Pública } \\
1997^{(1)}\end{array}$ & $\begin{array}{c}\text { Opinión } \\
\text { Pública } \\
1998^{(2)}\end{array}$ & $\begin{array}{c}\text { Opinión } \\
\text { Pública } \\
1999^{(3)}\end{array}$ & $\begin{array}{c}\text { Opinión } \\
\text { Cadetes } \\
2001^{(4)}\end{array}$ & $\begin{array}{c}\text { Opinión } \\
\text { Pública } \\
2005^{(5)}\end{array}$ \\
\hline $\begin{array}{l}\text { Seguirán siendo necesarios } \\
\text { para la defensa }\end{array}$ & 46.3 & 50.0 & 47.8 & 26.1 & 53.3 \\
\hline $\begin{array}{l}\text { Acabarán por desaparecer } \\
\text { a corto o medio plazo }\end{array}$ & 9.2 & 7.5 & 7.3 & 9.9 & 6.1 \\
\hline $\begin{array}{l}\text { Se dedicarán sólo a intervenir en } \\
\text { catástrofesy ayuda humanitaria }\end{array}$ & 24.6 & 21.7 & 24.9 & 49.2 & 23.2 \\
\hline $\begin{array}{l}\text { Formarán parte de una policía } \\
\text { internacional }\end{array}$ & 9.7 & 9.7 & 10.2 & 12.1 & 8.6 \\
\hline Ns/Nc & 10.3 & 11.2 & 9.7 & 2.7 & 8.8 \\
\hline
\end{tabular}

(1) Estudio 2234 del Centro de Investigaciones Sociológicas

(2) Estudio 2277 del Centro de Investigaciones Sociológicas

(3) Estudio 2317 del Centro de Investigaciones Sociológicas

(4) Estudio 98/14 Instituto Universitario "General Gutiérrez Mellado"

(5) Estudio 2592 del Centro de Investigaciones Sociológicas

Con el panorama descrito se impone preguntarse: ¿la consolidación democrática española se ha extendido también a las FAS? ¿Han entendido que son administración del Estado y no un poder político? ¿Han comprendido y aceptado la supremacía civil que rige las relaciones civiles-militares?
¿Por qué existe una brecha todavía profunda entre la sociedad española y sus fuerzas armadas? ¿Qué elementos componen esa fractura? Para intentar resolver todas estas preguntas utilizaré los datos de varios proyectos de investigación (Martínez, 2002, 2003, 2004, 2007b; Caforio y Martínez, 2005; 
Martínez y Díaz 2005, 2007) en virtud de los cuales hemos conseguido entrevistar a todos los alumnos -más de 2500- que estaban formándose en las academias de oficial y suboficial, a una muestra significativa de estudiantes universitarios de las licenciaturas de derecho, económicas y políticas de cuatro universidades españolas (Universidad de Barcelona, Universidad de Granada, Universidad Rey Juan Carlos y Universidad de Burgos), a elites económicas, políticas, militares y de los medios de comunicación. Todo este acopio de datos nos permitirá por tanto acercarnos a la realidad actual de las relaciones civiles-militares y aproximarnos a algunos aspectos de la cultura política que atesoran los futuros mandos militares españoles.

Desde estos datos, entre las características que describen las relaciones civiles militares pueden citarse: (i) mejora de la opinión pública respecto de las FAS, (ii) la disonancia cognitiva militar respecto de la opinión pública sobre ellos, (iii) desprestigio de la profesión militar, (iv) poca confianza ciudadana en las FAS, (v) fuertes dificultades sociales para incrementar los presupuestos de Defensa, (vi) mayor apego a la idea de España que el resto de la ciudadanía y (vii) visión corporativa de la defensa por parte de los militares al tiempo que se asumen, sin ambages, la idea de supremacía civil. Estas dos últimas características nos llevan a la necesidad de ahondar en la cultura política de los militares. También desde los datos que disponemos, podemos afirmar que: (i) estamos ante un militar demócrata. (ii) ideológicamente conservador, (iii) nacionalista español y (iv) con dificultades de aceptación de los hechos diferenciales que implica la existencia de plurinacionalidad en España

\section{RELACIONES CIVILES MILITARES}

La imagen pública de los militares viene marcada por tres afirmaciones. Por un lado, la impresión que la opinión pública tiene de las FAS está mejorando paulatinamente. El simple análisis de la tabla 1 nos muestra cómo a mediados de la década de los ochenta eran más los ciudadanos que veían a los militares poco capacitados y hoy un $60 \%$ los estima capacitados para sus funciones. Incluso, un $55 \%$ de los futuros mandos militares creen que los militares están integrados en la sociedad (Martínez, 2007b, p. 141). Sin embargo, conviene ser cauto puesto que las futuras elites civiles (estudiantes universitarios de las licenciaturas de derecho, económicas y ciencia política) no creen que el objetivo de integrar plenamente a los militares en la sociedad se haya cumplido (Martínez y Díaz, 2005. p. 238). Es decir, la imagen mejora; pero está lejos de ser óptima (tabla 3).

Tabla 3. Imagen pública de las FAS en España

\begin{tabular}{|l|c|c|c|c|c|}
\hline & $\begin{array}{c}\text { Muy } \\
\text { Buena }\end{array}$ & $\begin{array}{c}\text { Bastante } \\
\text { Buena }\end{array}$ & Regular & Mala & Ns/Nc \\
\hline Cadetes & 0 & 20 & 56 & 17 & 7 \\
\hline Universitarios & 3 & 32 & 41 & 10 & 13 \\
\hline
\end{tabular}

Fuente: Martínez y Díaz, 2005

Por otro lado, hay una importante disonancia cognitiva en los militares respecto de la opinión pública. Es de sobra conocido que lo peyorativo, lo negativo, crece vertiginosamente, mientras que las corrientes positivas tardan en ser aceptadas. Así, la impresión que los cadetes tienen de cómo valora la opinión pública a las FAS es bastante más negativa de la expresada por la sociedad. Mientras que un $51 \%$ de los universitarios cree que la imagen pública de las FAS es mala, los cadetes elevan esa proporción hasta las tres cuartas partes. Esta disonancia cognitiva se ratifica al abordar el patriotismo o los sentimientos ante el himno y la bandera (Martínez, 2007b, pp. 149-151). Así, el $90 \%$ de los futuros mandos cree que el patriotismo es percibido socialmente con "indiferencia" o "cuestionado y rechazado" y en cambio, el $86 \%$ de la sociedad española manifiesta 
sentirse "muy" o "bastante" orgulloso de ser español. $\mathrm{Y}$ al requerirles sobre lo que la ciudadanía siente al escuchar el himno o ver la bandera, un $63 \%$ de los cadetes dice que "muy poca emoción" o "nada en especial"; $y$ en cambio, entre el conjunto de la población, un $63 \%$ en el caso de la bandera, y también en el del himno, dice sentir "una emoción muy fuerte" o "algo de emoción". No obstante, no se trata de un comportamiento esquizofrénico de los futuros mandos militares, sino una generalización de casos concretos. Es decir, ellos perciben cierta hostilidad social y ahí se desencadena una tensión que les lleva a sentirse poco integrados, a creer que para el futuro se les considerará innecesarios (tabla 2), a cuestionar el patriotismo de los españoles y su afinidad por los símbolos.

Lo que también puede estar ocurriendo es que el cadete identifique prestigio profesional con imagen pública. Y entramos en la tercera afirmación: la profesión militar goza de escaso prestigio social. Este sí que es escaso y ambos colectivos lo aprecian así. Es decir, la imagen de las FAS no es tan mala como los cadetes creen; pero la profesión militar está muy desprestigiada. Únicamente los sacerdotes, funcionarios, artistas y profesores de educación secundaria están por debajo del oficial militar en la escala de prestigio. Escala en la que por lo demás ambos mundos, civil y militar, coinciden en su ranking preferencial: primero profesiones liberales, segundo empresarios y tercero servicios. A pesar del desprestigio, un $90 \%$ de los cadetes están muy orgullosos de los hombres y mujeres que sirven en el ejército, algo que también ocurre con la mitad de los estudiantes universitarios (Martínez y Díaz, 2005, p. 240).

Resulta también significativa la poca confianza que las futuras elites civiles depositan en las FAS (tabla 4). Sin embargo, conviene remarcar que es una valoración en ascenso y que los ubica en una posición similar a los partidos políticos y los medios de comunicación y superior a la Banca y la patronal.

Tabla 4. Confianza en las instituciones

\begin{tabular}{|c|l|c|c|l|}
\hline Posicion & \multicolumn{3}{|c|}{ Cadetes } & \multicolumn{2}{c|}{ Media $^{(1)}$} & Universitarios \\
\hline \multicolumn{5}{|c|}{ Confianza } \\
\hline $1^{\circ}$ & Los Militares & $6^{\prime} 29$ & $6^{\prime} 49$ & Universidad \\
\hline $2^{\circ}$ & La policía & $6^{\prime} 16$ & $6^{\prime} 46$ & ONG's \\
\hline $3^{\circ}$ & Universidad & $6^{\prime} 00$ & $6^{\prime} 31$ & Parlamento \\
\hline $4^{\circ}$ & ONG's & $5^{\prime} 78$ & $5^{\prime} 56$ & La policía \\
\hline $5^{\circ}$ & Justicia & $5^{\prime} 63$ & $5^{\prime} 55$ & Presidente del Gobierno \\
\hline $6^{\circ}$ & Parlamento & $5^{\prime} 58$ & $5^{\prime} 50$ & Gobierno \\
\hline $7^{\circ}$ & Gobierno & $4^{\prime} 80$ & $5^{\prime} 48$ & Justicia \\
\hline $8^{\circ}$ & Banca & $4^{\prime} 70$ & $5^{\prime} 06$ & Sindicatos \\
\hline $9^{\circ}$ & Presidente del Gobierno & $4^{\prime} 67$ & $4^{\prime} 99$ & Partidos políticos \\
\hline $10^{\circ}$ & La Iglesia & $4^{\prime} 52$ & $4^{\prime} 70$ & Medios de comunicación \\
\hline $11^{\circ}$ & Empresarios & $4^{\prime} 42$ & $4^{\prime} 65$ & Los Militares \\
\hline $12^{\circ}$ & Medios de comunicación & $3^{\prime} 99$ & $4^{\prime} 46$ & Banca \\
\hline $13^{\circ}$ & Sindicatos & $3^{\prime} 92$ & $4^{\prime} 27$ & Empresarios \\
\hline $14^{\circ}$ & Partidos políticos & $3^{\prime} 83$ & $3^{\prime} 12$ & La Iglesia \\
\hline
\end{tabular}

(1) Usamos una escala de 1 a 10 en donde 1 significa ninguna confianza y 10 completa confianza. Fuente: Martínez y Díaz (2005). 
Como era de esperar, cadetes y universitarios depositan su confianza de modo distinto. Así, los cadetes confían en primer lugar en las instituciones de Seguridad y Defensa, en segundo término en las organizaciones más cercanas a la sociedad (la universidad y las ONG's; pero no así la Iglesia), en tercer término las instituciones básicas representativas de los tres poderes del Estado, en penúltimo lugar las vinculadas a la economía junto con la Iglesia y, finalmente, los actores básicos del sistema político, aquellos que han de poner en contacto a la sociedad con las instituciones de poder (partidos políticos, sindicatos y medios de comunicación). Es igualmente destacable que el gobierno y su primer ministro, así como la iglesia, los actores económicos y los políticos obtienen todos ellos un suspenso en cuanto a valoración de la confianza. Los universitarios generan un ranking de confianza diferente en el que destaca la ubicación trasera e inferior a cinco de las FAS, la mejor colocación de los actores políticos, terceros, aunque con valoraciones también por debajo de cinco y la última posición conferida a la Iglesia y a las instituciones económicas. Es decir, los universitarios confían en la Universidad y en las ONG's y en las instituciones representativas de los poderes legislativo, ejecutivo y judicial.

Seguramente en esta falta de confianza está una de las razones que explican las fuertes dificultades sociales para incrementar los presupuestos de
Defensa. Es cierto que la distancia del gasto español con respecto a sus homólogos europeos ha descendido; pero seguimos siendo uno de los países con menor gasto en Defensa; algo que hoy por hoy supone prevención, no ataque. El problema no es sólo que el presupuesto de defensa sea bajo respecto del PIB, sino que existe un rechazo social intenso al incremento del mismo. La principal medida defensiva es la prevención y esta es cara, poco vistosa y además suele tener fecha de caducidad. Aunque es cierto que, tras los atentados del 11-My del 11-S se ha incrementado la conciencia cívica sobre la necesidad de prevenir, sigue siendo socialmente complejo incrementar el presupuesto de defensa. Desde los albores democráticos la opinión pública española se ha caracterizado por su rechazo al gasto militar. Así, en 1986 un estudio del CIS 5 mostraba cómo un $35 \%$ de los ciudadanos creía que los gastos de Defensa eran excesivos -único área de gasto en la que ocurría-. Esta tónica se mantiene, pasada una década, en las cinco encuestas sobre profesionalización de las FAS, realizadas igualmente por el $\mathrm{CIS}^{6}$, donde una media del $23 \%$ de los españoles los sigue considerando excesivos. En el caso de las futuras elites civiles (tabla 5) la mayoría (36\%) se inclina por el mantenimiento o el ligero incremento, pero no conviene obviar que un 35\% aboga por su reducción. Como es lógico los cadetes $(76 \%)$ se inclinan por el aumento de la dotación presupuestaria.

Tabla 5. Opinión sobre el presupuesto de defensa

\begin{tabular}{|l|c|c|c|c|c|}
\hline & $\begin{array}{c}\text { Incremento } \\
\text { considerable }\end{array}$ & $\begin{array}{c}\text { Algo de } \\
\text { increment }\end{array}$ & $\begin{array}{c}\text { Permanecer } \\
\text { como está }\end{array}$ & $\begin{array}{c}\text { Algo de } \\
\text { decremento }\end{array}$ & $\begin{array}{c}\text { Decremento } \\
\text { considerable }\end{array}$ \\
\hline Estudiantes & 8 & 28 & 28 & 18 & 17 \\
\hline Cadetes & 47 & 29 & 8 & 7 & 10 \\
\hline
\end{tabular}

Fuente: Martínez y Díaz (2005)

Al abordar la mentalidad militar tres rasgos suelen ser siempre citados como parte esencial de la misma: son nacionalistas, son corporativos y son conservadores. Dos de estas cuestiones merecen nuestra atención en el ámbito de las relaciones civiles militares. El mayor apego a la idea de nación española que anida entre los futuros mandos militares y su intenso corporativismo, que no impide una radical aceptación de la

5 Centro de Investigaciones Sociológicas. Estudio n ${ }^{\circ} 1518$

$6 \quad$ Estudios 2234, 2277, 2317, 2379 y 2447. 
supremacía civil. Respecto del primer punto (tabla 6), las futuras elites civiles y militares han ubicado, como suele ser habitual, en primer lugar su esfera más próxima e íntima: la familia, los amigos y uno mismo. Igualmente, la "comunidad mundial" ha quedado relegada a los últimos lugares acompañada de "su comunidad religiosa"7. Lo más relevante aparece en los valores intermedios, sobre todo en lo referente a la posición y valoración de España y de su comunidad autónoma. Para los cadetes, tras el círculo íntimo aparece la identificación con el país, antes que con su región o su ciudad, hecho que revela un alto grado de compromiso para con la defensa territorial. Incluso su comunidad autónoma, en un Estado en donde la multinacionalidad es un constante elemento de debate político, queda por detrás de Europa. En cambio, los universitarios ubican la Comunidad autónoma y su ciudad antes que España; hecho este que, en sentido contrario, implica un mayor desapego para con su país 8 .

Tabla 6. Sentimiento de apego con personas y ámbitos

\begin{tabular}{|c|l|c|c|l|}
\hline Posición & \multicolumn{3}{|c|}{ Cadetes } & \multicolumn{3}{c|}{ Media $^{(1)}$} & \multicolumn{1}{c|}{ Estudiantes Universitarios } \\
\hline & \multicolumn{3}{|c|}{ con.. } \\
\hline $1^{\circ}$ & Su familia & $9^{\prime} 00$ & $8^{\prime} 95$ & Su familia \\
\hline $2^{\circ}$ & Usted mismo & $8^{\prime} 74$ & $8^{\prime} 58$ & Sus amigos \\
\hline $3^{\circ}$ & Sus amigos & $8^{\prime} 68$ & $8^{\prime} 49$ & Usted mismo \\
\hline $4^{\circ}$ & España & $8^{\prime} 67$ & $7^{\prime} 43$ & Su profesión, sus colegas \\
\hline $5^{\circ}$ & Su profesión, sus colegas & $8^{\prime} 07$ & $7^{\prime} 03$ & Su ambiente natural \\
\hline $6^{\circ}$ & Su ambiente natural & $6^{\prime} 82$ & $6^{\prime} 96$ & Su Comunidad Autónoma \\
\hline $7^{\circ}$ & Su ciudad de nacimiento & $6^{\prime} 63$ & $6^{\prime} 85$ & Su ciudad de nacimiento \\
\hline $8^{\circ}$ & Europa & $6^{\prime} 31$ & $6^{\prime} 80$ & España \\
\hline $9^{\circ}$ & Su Comunidad Autónoma & $6^{\prime} 29$ & $6^{\prime} 76$ & Europa \\
\hline $10^{\circ}$ & Su comunidad religiosa & $4^{\prime} 90$ & $5^{\prime} 77$ & La comunidad mundial \\
\hline $11^{\circ}$ & La comunidad mundial & $4^{\prime} 69$ & $3^{\prime} 38$ & Su comunidad religiosa \\
\hline
\end{tabular}

(1) Escala de 1 a 10 en donde 1 significa ningún apego y 10 completo apego. Fuente: Martínez y Díaz (2005).

Por último, corporativismo y control político. Existe una tendencia a equiparar compañerismo - una enorme virtud militar- con el corporativismo. Es evidente que nada hay que objetar al primero. En cambio, al socaire del corporativismo "lo que no puede en modo alguno pretenderse es perfilar un estamento segregado del común de los ciudadanos; bien al contrario, a las Academias les corresponde formar unos oficiales que se integren estrechamente en la sociedad de la que es obvio que forman parte y a la que deben defender en

$7 \quad$ Hoy los militares españoles están lejos de la religiosidad que se les presuponía. (Martínez; 2007b: 72-74)
8 Conviene dejar claro que en España existen comunidades autónomas, llamadas históricas, como Cataluña, País Vasco y Galicia en las que existe un importante, aunque minoritario, número de ciudadanos que desarrolla una identificación nacional subjetiva ajena a la española; se sienten preferente o exclusivamente catalanes, gallegos o vascos. Igualmente, los ciudadanos de Castilla suelen identificarse subjetivamente de modo preferente con la nación española. Finalmente, los ciudadanos del resto del país; es decir, la mayoría de los españoles, desarrollan una identificación nacional subjetiva dual: se sienten tan de su comunidad autónoma (aragoneses, andaluces, etc.) como españoles. Por ello, esta pregunta fue modificada respecto del cuestionario que se aplicó en toda Europa y se introdujo como ítem el ámbito regional. A la vista de que el resultado final de 
tiempos de peligro" (Fernández Segado, 1986, p. 59). Un exceso de celo corporativo puede llevar al aislamiento social y, lo que sería dramático, abrir el camino a la negación de la dirección política sobre la administración militar; es decir, al militarismo (Lleixà, 1986).

Un indicador del corporativismo es su preferencia sobre la naturaleza civil o militar que debería tener el ministro de defensa, el director general de política de defensa y el director del Centro Nacional de Inteligencia (Martínez 2007b). En los tres casos masivamente se inclinan por un militar ( $64 \%, 78 \%$ y $74 \%$ respectivamente) lo que denotaría un intenso talante corporativo. Igualmente, manifiestan un rechazo severo -ocho de cada diez- a la posibilidad de que en la designación de los altos mandos de las FAS pesen consideraciones de carácter político. La duda y el riesgo que podría plantear este tipo de respuestas es si se está revelando un carácter corporativo o militarista. Ante esa disyuntiva, dado el carácter netamente democrático que han revelado los cadetes y del que hablaré seguidamente, me inclino por considerar estos datos como la plasmación de una pretensión corporativa que busca intensificar la cohesión grupal.

Un tópico habitual entre los militares es sentirse olvidados, relegados, menospreciados... por la

universitarios podía estar muy sesgado por el de los estudiantes catalanes decidimos, para esta pregunta, extraer por separado los resultados.

El resultado final del análisis desagregado muestra que la identificación con España, como era esperable, crece entre los alumnos granadinos y se incrementa más en el caso de los castellano-leoneses y de los madrileños (6'28 los catalanes, 7'32 los granadinos y 7'98 los burgaleses junto a los madrileños). Por el contrario la identificación con su comunidad autónoma sigue un idéntico itinerario pero en sentido decreciente (7'24 los catalanes, 6'68 los granadinos y 6'31 los burgaleses junto a los madrileños). En definitiva, la idea plasmada en la tabla 7, de que los estudiantes universitarios sienten una identificación muy importante por su comunidad autónoma y mucho más irrelevante de España presenta, en nuestro caso, un sesgo que obedece al peso sobredimensionado que tienen los estudiantes catalanes en la muestra respecto de su peso global en todo el Estado. clase política; pero en cambio percibir que estos líderes, sí que están próximos a sus ciudadanos. Nuestros datos (Martínez y Díaz; 2005) ratifican la primera parte del axioma puesto que los cadetes creen que sus líderes políticos no están muy informados sobre las modernas fuerzas armadas (52\%); en cambio, los universitarios sí creen que lo están (59\%). Sin embargo, cadetes y universitarios no creen que los líderes políticos en general, compartan los mismos valores que su sociedad (50\% y $35 \%$ respectivamente). Ese desconocimiento no desacredita la idea de supremacía del poder civil respecto de la milicia. Así, un $63 \%$ de los cadetes lo cree un valor importante, un $68 \%$ cree que es un principio que se cumple en España y un 64 \% está de acuerdo con que el militar profesional está subordinado a los líderes políticos -iun $29 \%$ no!-. Por otro lado, sin renunciar a la supremacía civil reclaman (57\%) que los políticos deben conferir mayor autonomía profesional a los militares - de nuevo el corporativismo-. En cambio, los universitarios están conformes con la idea de subordinación militar (65\%); pero ni les resulta una cuestión importante (49\% sí frente a $39 \%$ no), ni creen que sea un principio rotundamente llevado a la práctica ( $44 \%$ sí frente a $43 \%$ no), aunque por el contrario, tampoco creen que deban disponer de autonomía profesional (47\%).

El rol político que estiman debe asumir un militar pasa por no criticar públicamente a los miembros del gobierno, ni a la sociedad civil (tabla 7). Tampoco deben tener influencia política directa sobre la sociedad, aunque los universitarios sí que creen que deben gozar de libertad de expresión sobre temas políticos como cualquier ciudadano. Los cadetes al rechazar esta opción simplemente están manifestando conocer las Reales Ordenanzas militares (texto que integra la regulación de los derechos de los militares y que fue aprobado a la vez que la Constitución de 1978); mientras que los universitarios al aceptarla seguramente les mueve el idealismo de limpieza e igualdad democrática que todavía no tiene en cuenta la necesaria limitación que requieren los derechos fundamentales de algunos ciudadanos para el correcto funcionamiento del Estado. Es 
decir, el cadete ya ha desarrollado un sentido de Estado que posiblemente el universitario no. Por último, no deben explicar y defender en público las políticas del gobierno, aunque sí deben defender públicamente las políticas de defensa que crean mejores para los intereses del país.

Tabla 7. Roles militares en la sociedad

\begin{tabular}{|l|c|c|}
\hline & Universitarios & Cadetes \\
\hline \multicolumn{2}{|c|}{ Acuerdo \% } \\
\hline $\begin{array}{l}\text { Los militares no deberían criticar públicamente a los miembros } \\
\text { del gobierno. }\end{array}$ & $55 \%$ & $78 \%$ \\
\hline Los militares no deberían criticar públicamente a la sociedad civil. & $66 \%$ & $82 \%$ \\
\hline $\begin{array}{l}\text { A los miembros militares se les debería permitir expresar } \\
\text { públicamente sus opiniones políticas como a otro ciudadano } \\
\text { cualquiera. }\end{array}$ & $63 \%$ & $38 \%$ \\
\hline $\begin{array}{l}\text { Está bien que los militares expliquen y defiendan en público } \\
\text { las políticas del gobierno. }\end{array}$ & $38 \%$ & $13 \%$ \\
\hline $\begin{array}{l}\text { Está bien que los militares defiendan públicamente las políticas } \\
\text { de defensa que creen son mejores para los intereses del país. }\end{array}$ & $71 \%$ & $63 \%$ \\
\hline $\begin{array}{l}\text { Está bien que los militares tengan una influencia política directa } \\
\text { en la sociedad. }\end{array}$ & $11 \%$ & $28 \%$ \\
\hline
\end{tabular}

Fuente: Martínez y Díaz (2005)

Finalmente, respecto de la importancia personal que atribuyen a algunos de los principios básicos de la democracia es evidente que la trilogía revolucionaria "liberté, égalité, fraternité" goza del respaldo entusiasta de cadetes y universitarios; y en menor medida la salvaguarda de la igualdad de oportunidades y responsabilidades (tabla 8). De igual manera, son principios a los que ambos atribuyen menor importancia la defensa del estilo de vida, la subordinación de las Fuerzas Armadas al liderazgo político y la integración de las Fuerzas Armadas en la sociedad -este último no presenta un sesgo tan radicalizado entre los cadetes-. Es un síntoma preocupante que para las futuras elites civiles las cuestiones de subordinación al poder civil e integración social, de los militares no sean, estimadas importantes $(49 \%$ y $38 \%$, respectivamente)

Tabla 8. Importancia personal y cumplimiento social de los principios democráticos

\begin{tabular}{|l|c|c|c|c|}
\hline \multirow{2}{*}{\multicolumn{1}{|c|}{ Principios democráticos }} & \multicolumn{2}{c|}{$\begin{array}{c}\text { ¿Cuan importante es para } \\
\text { usted..? }\end{array}$} & \multicolumn{2}{c|}{$\begin{array}{c}\text { ¿Se ha hecho realidad en } \\
\text { su país...? }\end{array}$} \\
\cline { 2 - 5 } & \multicolumn{2}{|c|}{ Muy importante \% ${ }^{(1)}$} & \multicolumn{2}{c|}{ Realizado \% ${ }^{(2)}$} \\
\cline { 2 - 5 } & Universitarios & Cadetes & Universitarios & Cadetes \\
\hline $\begin{array}{l}\text { Igualdad, con independencia del sexo, } \\
\text { la raza, la religión, etc. }\end{array}$ & 84 & 71 & 40 & 52 \\
\hline Respeto para las personas & 86 & 78 & 51 & 59 \\
\hline $\begin{array}{l}\text { Libertades básicas de las personas } \\
\text { (libertad de reunión, de pensamiento, } \\
\text { de expresión, de prensa, etc.) }\end{array}$ & 80 & 69 & 73 & 82 \\
\hline
\end{tabular}




\begin{tabular}{|l|c|c|c|c|}
\hline Respeto a la Constitución y los Estatutos. & 37 & 50 & 69 & 59 \\
\hline $\begin{array}{l}\text { Protección de las oportunidades y } \\
\text { responsabilidades de las personas }\end{array}$ & 43 & 37 & 49 & 49 \\
\hline Defensa del estilo de vida de la sociedad & 16 & 15 & 62 & 76 \\
\hline $\begin{array}{l}\text { Relaciones pacíficas con otras sociedades } \\
\text { en el mundo }\end{array}$ & 54 & 44 & 51 & 77 \\
\hline $\begin{array}{l}\text { Subordinación de las Fuerzas Armadas } \\
\text { al liderazgo político }\end{array}$ & 18 & 19 & 44 & 68 \\
\hline $\begin{array}{l}\text { Integración de las Fuerzas Armadas en } \\
\text { la sociedad }\end{array}$ & 9 & 40 & 33 & 40 \\
\hline
\end{tabular}

(1) Dado que la agregación de respuestas que confieren importancia arroja casi siempre cifras elevadísimas, sólo ciframos los porcentajes de quienes han respondido "muy importante"; pero subrayaremos aquellos que uniendo las respuestas "muy importante" y "bastante importante" resulten inferiores al $50 \%$

(2) Agregamos los datos de "bastante realizado" and "completamente realizado". Subrayaremos aquellos casos en los que el incumplimiento sea superior al cumplimiento.

Fuente: Martínez y Díaz (2005)

Igualmente, la percepción que unos y otros manifiestan del cumplimiento que los principios revolucionarios tienen en España es ajustada con el respeto, y crítica para con la igualdad, sobre todo por parte de los universitarios (un 58\% cree que no se cumple). El resto de los principios democráticos propuestos, con excepción de la integración social de lasFAS, muestra un aceptable nivel de cumplimiento. Sin embargo, hay que resaltar dos principios que presentan una importante divergencia en cuanto a la valoración de cadetes y universitarios. Así, para las futuras elites civiles el grado de cumplimiento del principio de relaciones pacíficas con otras sociedades en el mundo está veintiséis puntos por debajo (sin duda, el trasfondo de la invasión de Irak está ahí); y la subordinación de los militares al poder político veinticuatro puntos por debajo -casi hay equilibrio entre cumplimiento e incumplimiento dado que un $43 \%$ de los universitarios creen que este principio democrático se incumple-No obstante, lo más desalentador es la coincidencia en que la integración social de las FAS no se ha realizado; cinco de cada diez en ambos mundos, cree que es un principio incumplido.

\section{CULTURA POLÍTICA DE LOS MILITARES}

Al abordar este aspecto es obligado iniciar resaltando el evidente carácter democrático de los futuros oficiales y suboficiales españoles, así como la profunda y positiva evolución que en muchos sentidos se ha desarrollado y que debiera posibilitar un más fluido acercamiento entre la sociedad civil y la Administración militar. En definitiva, estamos ante un militar moderno en su profesión, conservador en sus ideas y muy similar al de los ejércitos del ámbito europeo democrático ${ }^{5}$. Atendiendo a los indicadores sobre los principios democráticos de gobierno y de la legitimidad de la democracia en España cabe afirmar que los cadetes, al igual que el conjunto de la sociedad española, presentan una aceptación solvente de la democracia al tiempo que manejan actitudes críticas respecto de algunos actores y componentes básicos de la misma. Es decir, los principios generales del régimen democrático están bien establecidos entre la población, pero la valoración que se hace de ella y de los actores que intervienen es menor, y la disposición personal a participar en acciones políticas, inexistente.

9 Ésta es la principal conclusión de la confrontación que hemos extraído (Caforio y Martínez, 2005) de los datos de los cadetes españoles y los europeos. Se trata de un alumno similar a cualquier cadete europeo. Evidentemente con algunos matices propios; pero, en líneas generales, muy similar. 
Un $92 \%$, de los futuros mandos militares considera la democracia como el mejor sistema político (Martínez, 2007b). La situación varía al preguntarles por el rendimiento del sistema político puesto que el porcentaje de los que creen que la democracia permite solucionar los problemas que tiene España se sitúa en el $70 \%$. La legitimidad es la creencia de que el sistema político democrático es más deseable que cualquier otro para ese país y no conviene confundirla con la eficacia. Esta diferenciación hace posible que instituciones legítimas, consideradas por tanto como las mejores para el país, pueden no solucionar los problemas o que incluso instituciones consideradas ilegítimas se conciban como eficaces. Paro, terrorismo y problemas de importancia similar son contextos que pueden hacer bajar la eficacia.

El resto de indicadores utilizados hacen referencia a la calidad de la propia democracia, lo que clásicamente ha sido etiquetado como eficacia política. Aquí los resultados no difieren en exceso del total de jóvenes españoles. Tanto lo que se refiere al interés político subjetivo, como a la eficacia política subjetiva interna y externa, la variación de los porcentajes es poco significativa. Por lo tanto, se desarrolla también entre los cadetes una característica propia de la cultura política española: el "cinismo democrático". Es decir, los principios generales del régimen democrático están bien establecidos entre la población, pero la valoración que se hace de la democracia y de los actores que intervienen es menor, y la disposición personal a participar en acciones políticas, inexistente.

Respecto de la autoubicación ideológica, tal y como he advertido, estamos ante un perfil conservador. La media entre los alumnos de academias militares está situada en el 6.3, es decir, en una posición de derecha moderada. Pero las medidas de tendencia central pueden llevar a equívocos, al no tener en cuenta la dispersión de los valores. Por lo tanto, será más real observar la distribución de los valores. A partir de la Tabla 9, queda claro que más de una cuarta parte del universo de estudio se sitúa en las posiciones más escoradas de la derecha (8-10), porcentaje que aumenta siete puntos en los alumnos en formación para ser oficiales ${ }^{10}$.

Tabla 9. Distribución de preferencias ideológicas

\begin{tabular}{|l|c|c|c|c|c|}
\hline & $\begin{array}{c}\text { Juventud } \\
\text { Octubre 1997 }\end{array}$ & $\begin{array}{c}\text { Alumnos } \\
\text { Enero/febrero 2001 }\end{array}$ & $\begin{array}{c}\text { Enero } \\
2001\end{array}$ & $\begin{array}{c}\text { Febrero } \\
2001\end{array}$ & $\begin{array}{c}\text { Marzo } \\
2002\end{array}$ \\
\hline Izquierda (1 2) & 9.1 & 3.5 & 4.7 & 6.2 & 5.2 \\
\hline$(34)$ & 25.1 & 10.8 & 27.6 & 24.5 & 23.7 \\
\hline$(56)$ & 31.5 & 35.4 & 31.2 & 29.6 & 29.8 \\
\hline$(78)$ & 10.2 & 32.4 & 9.7 & 9.1 & 9.3 \\
\hline Derecha (910) & 1.9 & 11.3 & 1.6 & 1.6 & 1.6 \\
\hline Ns/Nc & 22.2 & 6.4 & 25.2 & 29.1 & 30.2 \\
\hline (N) & $(2423)$ & $(2458)$ & $(2486)$ & $(2498)$ & $(2499)$ \\
\hline Media & 4.64 & 6.27 & 4.77 & 4.70 & 4.81 \\
\hline Desviación Típica & 1.87 & 2.02 & 1.69 & 1.79 & 1.76 \\
\hline (N) & $(1884)$ & $(2300)$ & $(1859)$ & $(1773)$ & $(1738)$ \\
\hline
\end{tabular}

Fuente: CIS Estudio 2257 e Instituto de la Juventud Octubre 1997 Barómetro CIS Enero 2001. Estudio 2406. Barómetro CIS Febrero 2001. Estudio 2409. Barómetro CIS Marzo 2002. Estudio 2448

Esta distribución de las preferencias ideológicas difiere de la que se produce entre los jóvenes españoles (Gráfico 1). La estructura de la curva de los alumnos de las academias militares es claramente bimodal, mientras que la de los jóvenes españoles es unimodal y muy centrada.
10 Nunciari (1998) muestra como los ejércitos de Dinamarca, Holanda y Suecia sus cadetes son de derechas en porcentajes superiores al $60 \%$; como el italiano, aun siendo ideológicamente de derechas presenta más de un $24 \%$ de extrema derecha; o como suizos, checos y lituanos son principalmente de centro mientras que casi un $70 \%$ de los polacos son de izquierda o extrema izquierda 
Por lo tanto, presenta una similitud en los valores de centro y disimilitudes en los valores tanto de izquierda como de derecha, si bien la distancia máxima se produce en los valores de derecha ( 7 y 8). Los futuros oficiales (alumnos de la Escala Superior de Oficiales, ESO), con la moda en ocho, son los que marcan mayores distancias con la juventud española.

Gráfico 1. Autoubicación ideológica de la juventud y de los alumnos por escalas

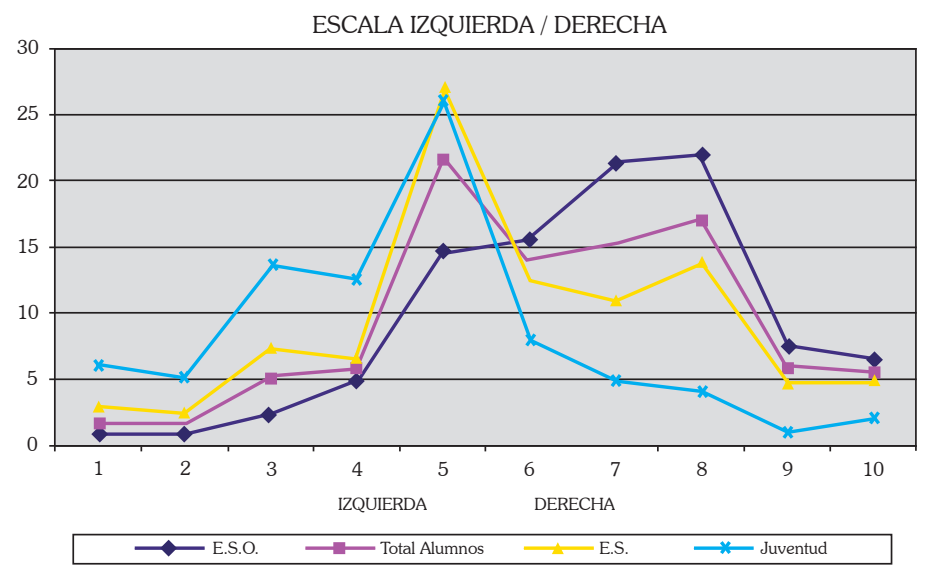

En España, habida cuenta la actual organización territorial del Estado y dada la presencia de sectores que cuestionan su adscripción a la nación española, vienen estudiándose, desde la transición, los sentimientos de pertenencia y los nacionalismos. Para tratar de medir este tipo de orientaciones se han utilizado diversos instrumentos, entre los que destaca la identificación nacional subjetiva (INS). Se trata de un indicador de sentimientos afectivos con el que se capta el reconocimiento de los individuos hacia determinadas comunidades y con el que puede ponderarse la distribución poblacional de estos apoyos, al plantearles en una escala la contraposición entre el referente estatal y aquellos con los que rivaliza.

Ateniendo a este indicador, las opiniones de los alumnos muestran una clara lealtad hacia la opción española, ya que dos terceras partes se consideran únicamente españoles o más españoles que de su comunidad autónoma. Esta concentración de las repuestas en el eje de la identificación nacional subjetiva ya hemos señalado que es una constante en los ejércitos de las democracias occidentales. En cambio lo que sí resulta significativo es la gran diferencia de la estructura de respuestas entre los alumnos de las academias militares y el total de jóvenes españoles (Gráfico 2).

Gráfico 2. Distribución de la Identificación nacional subjetiva según los jóvenes españoles y los alumnos de las academias

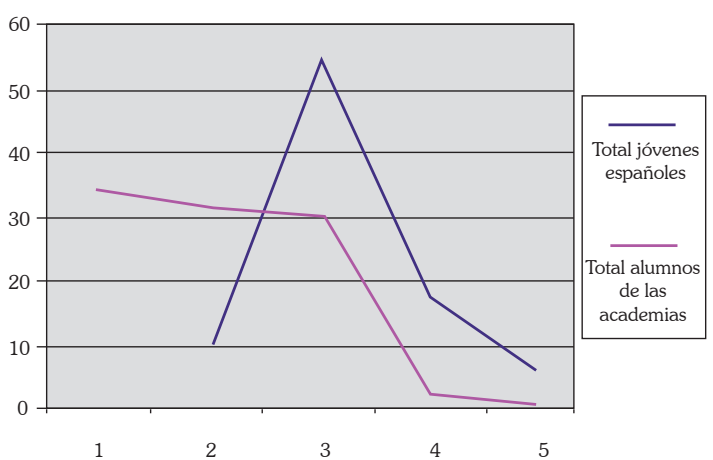

1: Únicamente español.

2: Más español que de la comunidad autónoma.

3: Tan español como de la comunidad autónoma.

4: Más de la comunidad autónoma que español.

5: Únicamente de la comunidad autónoma.

Fuente: Para el total de los jóvenes, Moral y Mateos (1999), para los alumnos militares Martínez (2007b)

Fuente: Para el total de los jóvenes, Moral y Mateos (1999), para los alumnos ESO y ES, Martínez (2007b) 
Las curvas que definen a los dos colectivos tienen muy pocos elementos en común. Mientras entre los jóvenes la estructura es claramente unimodal, entre los alumnos de las academias militares el grupo mayoritario se sitúa en posiciones que marcan claramente una identificación nacional española, hasta el punto que dos terceras partes se declaran únicamente españoles o más españoles que de la comunidad autónoma, en contraste con la juventud civil entre los que este porcentaje se sitúa en el $20 \%$. El Gráfico 3 muestra cómo se acentúa más esta convicción entre los futuros oficiales (ESO) que entre los futuros suboficiales (ES).

Gráfico 3. Distribución de la Identificación nacional subjetiva según los jóvenes españoles y futuros oficiales y suboficiales españoles.

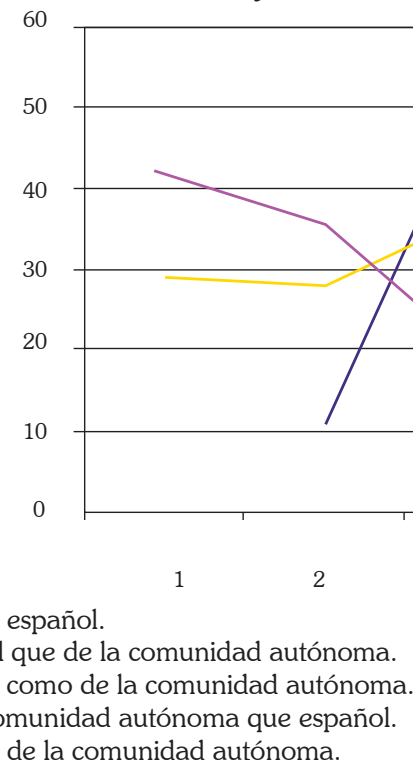

Las actitudes sobre la dimensión territorialcultural también pueden ser interpretadas como una orientación ideológico-política y diferenciada de los sentimientos de identificación nacional. Uno de los indicadores utilizados para captarlas es una escala que sintetiza de forma aproximada una diversidad de posiciones ante el objetivo de construir y/o favorecer los intereses de dos referentes contrapuestos. Atendiendo a este nuevo indicador la gran mayoría de los alumnos aceptan la distribución territorial del poder que forja el actual Estado de las autonomías. Así se desprende del hecho que dos terceras partes de los alumnos de las academias, ante la posibilidad por optar en un continuum en el que en el que los extremos están definidos por un Estado centralizado y un Estado confederal, deciden escoger la fórmula de descentralización territorial vigente en la actualidad $^{11}$. Sin embargo, es preciso poner de relieve que una cuarta parte de los entrevistados apuestan por un sistema político centralizado; $1 / 3$ en el caso de los cadetes. Esta concentración de respuestas es claramente dispar respecto del total de la juventud española ya que el modelo de Estado

11 La pregunta en concreto decía: Aquí tiene algunas fórmulas alternativas de la organización territorial del Estado en España. Señale, por favor, ¿con cuál de ellas está usted más de acuerdo?

a/ Un Estado con un único Gobierno central y sin autonomías

b/ Un Estado con Comunidades Autónomas, como en la actualidad

c/ Un Estado en el que las Comunidades Autónomas tengan mayor autonomía que en la actualidad d/ Un Estado en el que se reconociese a las Comunidades Autónomas la posibilidad de convertirse en Estados independientes 
centralizado sólo es preferido por un $8 \%$ (Moral y Mateos, 1999). No existe contradicción alguna entre tener una identificación nacional de claro carácter español y considerar que la mejor forma de organizar territorialmente el Estado español es el de un Estado políticamente descentralizado. La mezcla de estas dos proposiciones es las que define a la mayoría de los alumnos de las academias militares.

\section{CONCLUSIONES}

Creo que las características que he apuntado como definitorias de las relaciones civiles militares y de la cultura política de los futuros mandos militares españoles han quedado suficientemente demostradas. No son desde luego todas las piezas que componen ese complejo puzzle, pero se trata, sin duda, de las principales. Es evidente que desde los inicios de la transición, allá por 1975, a nuestros días se ha avanzado mucho, y bien, en el camino de asentar unas fuerzas armadas consolidadas democráticamente, conscientes de su rol de administración del Estado al servicio del gobierno y más cercanas e imbricadas en el tejido social. Pero también es seguro que falta todavía camino por recorrer.

La sociedad española es muy compleja en su valoración y aceptación de la necesidad de defensa y del actor principal de la misma, las fuerzas armadas. La guerra civil y el franquismo quedan cada vez más lejos; pero sólo una labor constante y tenaz eliminará muchos de los miedos y recelos que todavía perviven en la sociedad española. En ese recorrido nada ayudan, por ejemplo, algunas $\mathrm{m}$ militares tuvieron recientemente con motivo de la reforma del Estatuto de Autonomía de Cataluña ${ }^{12}$. Sin embargo, sería injusto juzgar

12 El Teniente General José Mena Aguada, general jefe de la fuerza terrestre, durante el discurso de la Pascua militar el 6 de enero de 2006 manifestó: "siempre he recalcado que los militares no debemos entrar en disquisiciones políticas, que lógicamente corresponden a los políticos, ahora bien, es nuestra obligación alertar (...) afortunadamente, la Constitución marca una serie de límites infranqueables para cualquier estatuto de autonomía, de ahí que reitero mi mensaje de tranquilidad (...) si esos límites fuesen sobrepasados, a toda la institución por unos pocos. Hoy las FAS españolas no son el rescoldo del franquismo. Son, lisa y llanamente, una administración pública al servicio del gobierno de un sistema político democrático.

La opinión pública seguirá mejorando conforme la actuación de los militares siga siendo profesional y no política. Al igual que su acertada actuación en operaciones de paz y en auxilio en catástrofes y calamidades incrementará la confianza ciudadana en la institución. Por otro lado, los militares han de hacer un esfuerzo por alejar de sí el victimismo de creerse postergados, rechazados e injustamente valorados. Fundamentalmente porque esas afirmaciones cada vez se ajustan menos a la valoración social. Queda camino por recorrer en España en el objetivo de articular unas relaciones civiles militares en las que predomine la confianza recíproca; pero cada vez es menor.

Hoy en día los futuros oficiales son ciudadanos perfectamente demócratas y con una innegable asunción de la supremacía del poder político. Las FAS españolas se han modernizado y resultan homologables a las de sus socios europeos como lo demuestra su perfecta incorporación a los sucesivos proyectos y misiones militares de la UE. Desde el ámbito de la cultura política, seguramente el mayor problema que hoy existe es que en los centros de formación militar nadie

lo cual en estos momentos afortunadamente parece impensable, sería de aplicación el artículo octavo de la Constitución: las fuerzas armadas, constituidas por el Ejercito de Tierra, la Armada y el Ejercito del Aire, tienen como misión garantizar la soberanía e independencia de España, defender su integridad, y el ordenamiento constitucional (...) el hecho de que en una autonomía sea exigible el conocimiento de su lengua particular es una aspiración desmesurada que obligaría en las fuerzas armadas a regular los destinos a esa autonomía de la misma forma que actualmente se regulan los destinos en el extranjero" El revuelo político fue intenso y el Ministro de Defensa lo arrestó el 7 de enero y el Consej o de ministros, a petición del Jefe del Estado mayor de la Defensa, lo cesó en su cargo el 13 de enero de ese año. Fueron varias las cartas de militares en la reserva publicadas en los medios apoyando las palabras del Teniente General. 
imbuye a los alumnos la idea de que España se constituye como unidad gracias a la diversidad y que precisamente son esas diferencias su riqueza. Y que su misión, como garantes del ordenamiento constitucional y defensores de la integridad territorial, es protegerlas. Puede que este esfuerzo pedagógico sea necesario en muchos más ámbitos y estratos de nuestra sociedad, incluso es evidente que la historia de España se escribe en los últimos doscientos años muy vinculada a los problemas de la articulación territorial del poder. Pero también es obvio que quien tiene como misión la defensa de la integridad territorial y del ordenamiento constitucional ha de tener clarísimo que la unidad no se cifra en la homogeneidad sino en la existencia indubitable, y constitucionalmente reconocida, de nacionalidades y regiones; es decir, en la plurinacionalidad. Por lo demás, la plurinacionalidad en nada mina, o debiera minar, los pilares de la unidad estatal.

\section{BIBLIOGRAFÍA}

BALLBÉ, M. (1983) Orden público y militarismo en la España constitucional: 1812-1983, Madrid, Alianza.

CAFORIO G. y MARTÍNEZ R. (2005) "The Spanish Cadet in the European Military Context: a Comparative Analysis of the Professional Socialisation", Working Papers ICPS n (en prensa), Barcelona, Institut de Ciències Polítiques i Socials.

FERNÁNDEZ, J. (2004) Texto policopiado. "Apuntes para una conferencia: Veinticinco años de Constitución y Fuerzas Armadas". Conferencia impartida en el Mando Regional Pirenaico el 22 de abril en el Palacio de Capitanía de Barcelona.

FERNÁNDEZ SEGADO, F. (1986) "Fuerzas Armadas-Sociedad: del mutuo aislamiento a la progresiva integración" Revista Española de Investigaciones Sociológicas, n 36, págs. 35-76.

LLEIXÀ, J. (1986) Cien años de militarismo en España, Barcelona, Anagrama.
MARTÍNEZ, R. (2002) "Perfil político institucional de la futura oficialidad y suboficialidad", Revista española de Ciencia Política , $\mathrm{n}^{\circ} 7$., pp.161-182.

- (2003) "Tipología profesional de la futura oficialidad y suboficialidad del ejército español" Cuadernos de Gestión y Administración Pública $n^{\circ} 3$

- (2004) "Quiénes son y qué piensan los futuros oficiales y suboficiales del ejército español" Documentos CIDOB de Seguridad y Defensa $\mathrm{n}^{\circ} 2$.

- (2007a) "Cultura política sobre Inteligencia: Hacia un encuentro con la sociedad" en Navarro Bonilla y Esteban Navarro (ed) Terrorismo global. Gestión de información y servicios de inteligencia, Madrid, Plaza y Valdes Ed.

- (2007b) Los mandos de las fuerzas armadas españolas del siglo XXI, Madrid, Centro de Investigaciones Sociológicas.

MARTÍNEZ, R. y DÍAZ, A. (2005) "Spain: an equation with difficult solutions" en Caforio y Kümmel (eds.) Military Missions and Their Implications Reconsidered: The Aftermath of September 11th, ELSEVIER

- (2007) "Threat Perception: New Risks, New Threats and New Missions" en Caforio (ed.) Cultural Differences between the Military and Parent Society in Democratic Countries, ELSEVIER

MARTÍNEZ, R., MAGRE, J., CALVET, J. y DÍAZ, A. (2002) "Perfil político institucional de la futura oficialidad y suboficialidad", Revista española de Ciencia Política , n 7.

MORAL, L, F. Y MATEOS, (1999) A. La identidad nacional de los jóvenes y el Estado de las Autonomías. Madrid: Centro de Investigaciones Sociológicas, (Opiniones y Actitudes, núm. 26).

NUNCIARI (1998) "Value Orientations and Political Attitudes of Cadets in a Comparative View" en Caforio, G. (ed.) (1998) The European Cadet: Professional Socialisation in Military Academies. Acrossnational Study, Badem-Badem, Nomos Verlagsgesellschaft 
PAYNE, S.G. (1968) Los militares y la política en la España contemporánea, París, Ruedo Ibérico.

- (1977) Ejército y sociedad en la España liberal: 1808-1936, Madrid, AKAL, colección Manifiesto.

SERRA SERRA, Narcis (2002) "El control de las fuerzas armadas en la transición democrática" en
Fundación CIDOB, Nuevos temas de seguridad en América Latina, Barcelona, CIDOB.

SERRANO, C. (1976) La Guerre d'Afrique et ses répercussions en Espagne: idéologies et colonialisme en Espagne 1859-1904, París, PUF.

- (1984) Final del Imperio: España 1895-1898 Madrid, Siglo XXI. 